\title{
Effective and Health Ways of Minimizing Eruption of COVID-19
}

\author{
Eliphus Ndereba ${ }^{1,}$, , James Akuma ${ }^{2, ~ * ~}$ \\ ${ }^{1}$ Department of Communication, Media, Film and Theatre Arts, Kenyatta University, Nairobi, Kenya \\ ${ }^{2}$ Department of Statistics and Actuarial Sciences, Jomo Kenyatta University of Agriculture and Technology, Nairobi, Kenya
}

Email address:

eliphusndereba@gmail.com (E. Ndereba), Jamesakuma440@gmail.com (J. Akuma)

${ }^{*}$ Corresponding author

\section{To cite this article:}

Eliphus Ndereba, James Akuma. Effective and Health Ways of Minimizing Eruption of COVID-19. European Journal of Preventive Medicine. Vol. 8, No. 4, 2020, pp. 36-42. doi: 10.11648/j.ejpm.20200804.11

Received: April 9, 2020; Accepted: May 3, 2020; Published: June 9, 2020

\begin{abstract}
The phylogenetic analyses that have been done on the emergence and causative agents of the 2019 novel Coronavirus Disease have focused on the epidemiology and the identification of the specific causative agents linked to Severe Acute Respiratory Syndrome for Corona viruses (SARS-COV), the viral pathogen that causes SARS-COV-2 (Currently, COVID-19). The virus is associated mostly with bats' genetic composition that's detrimental to Human cells if in contact. Although there are readily established measures to curb the outbreak and transmission of the disease, there is much yet to be done especially in the affected African countries where most medics rely on the abroad research guidance. The world's Medical attendants have been left with a dire need to establish the sufficiently effective and immediate measures and/ or guidelines on how to minimize the outbreak and widespread interspecies infections of SARS-COVs. Apart from the ways identified by the World Health Organization, there are several other strategies that the African countries can rely on to mitigate the outbreak of SARS-COV-2 which has always been diagnostically experienced as respiratory tract disorders: Pneumonia. Among the widely implemented measures in most nations are: quarantining the suspected victims and infected individuals, partial/total lockdowns, abolishment of (over) crowding, abolishment of bare handshakes, encouraging keeping of the social distance, use of gloves and masks, use of disinfectants on public resources and premises, using sanitizers for hand washing and banning air transport to prevent import or export of new COVID-19 infections.
\end{abstract}

Keywords: Phylogenetic, SARS-COV, SARS-COV-2

\section{Background of the Study}

The ongoing eruption of the 2019 Coronavirus disease is linked to a seafood market in Wuhan city located in southern china at a province called Hubei towards the end of December 2019. This viral disease has been found to have very similar genetic homology with Severe Acute Respiratory Syndrome of Coronavirus (SARS-COV) and middle East Respiratory Syndrome of Coronavirus (MERSCOV) [1] The animals' meats sold were acquired from both domestic and wild animals such as Bats, Carmel, Cattle, and cats [2, 3]. World Health Organization contended that the social media platforms confirmed that snakes, birds and other small mammals including marmots and bats were part of the commodities in the market which would also have ushered to the emergence and/or outbreak of the 2019 novel coronavirus disease. These meats are reported to harbor the coronavirus zoonotic pathogen. But the National Health Commission of People's Republic of China [4] considered that the animal coronaviruses cannot be transmitted to human beings. This assertion is backed up by the fact that the Carmel and cattle meat has always been being consumed in all parts of the world and COVID-19 did not emerge from livestock slaughterhouses or butcheries. The current novel Coronavirus disease was announced to have firstly appeared as concentrated pneumonic occurrences by the Wuhan Municipal Health Commission.

[5] It was demonstrated that SARS-COV-2 is homologous to the 2002 China's outbreak. The epidemic infection is also related to 1918 influenza pandemic in which individuals portrayed the signs of influenza within 4-5days and then 
pneumonia leading to death [6]. It resulted from London and the methods that were used to mitigate it are currently effective towards its control. This was encountered when the pathogenic human Coronavirus had emerged and transmitted to human from animal sold in a humid market area for both cases. It was demonstrated that SARS-COV viral RNA in raccoon dogs and palm civets sold in these humid markets acted as the source of the 2002 Coronavirus outbreak [7]. While, other researchers argued that 2019 novel coronavirus disease resulted from consumption of codon derived from the snake [8], an assertion that was refuted by other researchers.

Another phylogenetic analysis done by the Chinese Life science panel based on a comparison of genomic sequencing of the novel 2019 corona in relation to SARS-COV and MERS-COV demonstrated that the causative agent responsible for the eruption of SARS-COV-2 is almost identical to SARS-COV in human beings as initially done in [1]. While in a published journal of virology still done in Chinese research plant, the Severe Acute Respiratory Syndrome for coronavirus (SARS-COV) is the zoonotic pathogen that caused the 2002 outbreak for SARS-Like coronavirus In China [9]. SARS-COV structures captured in the laboratory analytical research appeared to be using identical molecule referred to as Angiotensin-converting Enzyme ACE2 for cellular entry which is a chemical product of angiotensin-converting enzyme in human body acquired from the conversion of Angiotensin-converting enzyme I into angiotensin-converting enzyme II. In the same research, another analysis carried out on the syndrome-like Coronavirus strain belonging to the bat, it was demonstrated that there is an homology in function in relation to human ACE2 via the establishment of an infectious complementary deoxyribonucleic acid clone [10]. Since the SARS-like coronavirus of the native bat was found to be identically functioning just as in human somatic cells without any harm and chromosomal mutations, it was demonstrated that there is a high tendency of interspecies transmissions and other homologous coronaviruses found within natural sources [11].

With the above analysis we should be able to note that consumption of bats' meat has the highest probability of being the origin of the 2019 novel coronavirus disease. The conclusive studies on this have already been established while vaccines and the actual remedies are yet to be realized. The types of Severe Acute Respiratory SyndromeCoronaviruses that are possibly found in bats are divided into three generic members named Alpha coronavirus, Beta coronavirus and Gamma coronaviruses [12]. As it was established in the Chinese in the Chinese Life science study, Beta coronavirus is the generic pathogen of Coronavirus that is responsible to the infection of human beings. According to Beta coronavirus is defined as the enveloped single-stranded RNA virus that infects wild animals, herds and human beings. Though genera beta coronavirus is believed to lack specific symptoms, COVID-19 has been realized to assume unsystematically unpredictable signs and symptoms such as pneumonia, fever, breathing difficulty, fever, fatigue, phlegm, conjunctival congestion, sore throat, migraine, joint pains, chills, nausea or vomiting, nasal blockage, dry and/or bloody cough and diarrhea [13]. The signs appear after the incubation period either 4-5 days, and even sometimes may go up to 20 days before the signs appear.

During the early period of the outbreak of this virus, most cases reported in Kenya were within Nairobi city and mostly linked to the Kenyans who had traveled back to the countryimported cases.

In addition to the above, the topics below are fundamentally significant for this study.

\section{Current Control Measures}

These occasions have led all the world public health officers into establishment of several measures among them being extension of holidays, total/partial lockdowns, market decentralizations and disinfection of the sales warehouses, abolishment of overcrowdings, public and/or private hospitalization and administering quarantines to the victims of coronavirus disease and self-sanitation politics. These mitigation practices have been financially facilitated by the respective local governments and financially stable patriots, World Health Organizations (WHO), Global monetary financiers, FBOs and NGOs.

\section{Temperature}

As john P. Cunha [14] notes in his essay for fever in adults and children, temperature for a normal human being should not exceed 37 degrees Celsius. One of the reasons why the bats cannot be affected by the coronavirus pathogens is that they have a tendency of raising their body temperatures than the viral pathogens can do in them. The temperature that is being indicated as fever in human beings is due to human's body inability to raise temperature beyond 98.6 degrees Fahrenheit and/or 37 degrees Celsius, an extent to which the coronavirus pathogens can survive thus multiplying and harms human beings. Yet they require slightly more than 40 degrees Celsius which makes the bats accommodate the viral pathogens and remain harmless to their bodies [15].

With the above notions, we can now refer to the emergence of the novel coronavirus which emerged in the winter season of china, favorable temperature for survival and rapid replications of the virus as well as speeding spread and transmission of the actual disease. The low temperature favored the pathogens and their attack on human beings as found in the wet areas where the sales for the bat meats were made in Wuhan city. Winter in China, USA, Italy and Spain is experienced during the months of December, January and February, the time when the disease was realized in china and currently has widely spread to other parts of the world due to global massive movements that have been taking place.

In relation to this, most studies states that coronaviruses multiply extremely and last long in low temperatures than in hot environments. In 2002 the pathogen that was transmitted to human being by the animals was found in sales done in humid areas during winter seasons still in southern china [7]. 
While [16] confirms that the coronavirus diseases have 'rapidly spread across the world due to massive migration of people.

\section{Kenyan Situation}

Kenyans acquired coronavirus disease from the foreign air travelers who have been infected by the virus. And right from the first case of COVID-19, the government established all the relevantly appropriate measures that have been established by the states that have encountered the same challenges. The country also imported the viral disease when the levels of temperature were low and experiencing heavy rains in some parts whereas some other parts were dry. With the urbanized geographical regions such as Nairobi, Kilifi, Mombasa, Busia and Kwale counties experiencing more cases than other places. Mostly, COVID-19 emerged in the highest annual human global movements. i.e., the Spring Festival travel season, which promoted a rapid national and global spread of COVID-19 [17].

Temperatures in rainy season; both short/light rains and heavy/ long rains are mostly accompanied by low temperatures. According to Kenya meteorological Department (KMD, 2020) some of the Western regions of the country are expected to experience some rains in March, April and May, whereas, these are the areas that are attacked by coronavirus disease. Since it's more rapid where the temperatures are low and the places are wet, the ministry of health should make sure that the disease does not spread largely to prevent massive loss of lives as well as huge budgets for catering for the medical services on the hospitalized and quarantined patients.

\section{Health Care Distance}

In most health centers serving as the quarantine spots, the victims of 2019-COVID have been found to transmit the viral pathogens to the Heath officers and other medical caretakers obliged to their needs [18]. To curb this, strict measures needs to be set. For example, shared resources between the victims and the health assistants must be marked for identification and isolation. These resources require be continuously disinfecting and changing from time to time to prevent the people mandatorily in these areas from contracting the disease. Failure to protect the health staff will lead to super spreading incidents whereby the staff will be the main agents for the transmissibility by receiving the virus and delivering it to all other people, both the quarantined and the potential patients of the viral disease.

\section{Mass Training and Seminars}

To secure the economic growth and development [19] most African governments need to train their citizens on how to react and handle SARS-like coronavirus symptoms or any queer changes in their bodies in terms of health. This is by providing them with further info about the coronavirus via the strategies that may be recommended in this and other researches. This is because the disease that is commonly transferable to human beings is the Genera Beta coronavirus disease which does not have any apparent symptoms or signs of definition and identification. Therefore, most of the patients sense the viral disease when it had begun to severely hamper the respiratory tract from normal functioning, a symptom which is almost the peak stage of the virus [20]. Sharing such information with all the people in all areas will help to diminish the propagated treatment for coronavirus disease and control of outbreak amongst the masses. For instance, [2] asserts that use of masks by uninfected people is not recommended in a public places to prevent contracting the viral disease. This statement is completely misleading as it's evidentially and scientifically observed that they are chiefly being effective in control of the transmissions. In addition to this, use of hand Sanitizers are being stressed as they will prevent the health individuals from transferring the Viral pathogens from the surfaces they touch to their openings [21] such as mouth, Nose, eyes, etc.

Psychological immunity is also very important to boost the health of the infected individuals. This is because their perception of their recovery from COVID-19 needs motivation to avoid stress and depression which may further weaken their genetic immune system. This can be facilitated by providing the patients with a glass of Aloe Vera juice at least twice a day [22].

This may also be done through playing light/soft music like rhumba which may tend to brush off regrets, imaginative physiological defeat and confine them within logic reasoning perspectives that are healthy. Encouraging music may be used to impose hopefulness into their minds to promote psychological calmness allowing the brain to swiftly coordinate the immune system and anti-viral activities in their bodies.

In relation to this, the mass also needs dietary erudition on the increment of vitamins which they must include in their meals to enrich their bodies with strong defense nutrients to protect and prevent their somatic cells against attack and destruction by the SARSCOV and COVID-19 Respectively.

\section{Recommendations for Readily Available Natural Treatments}

What most vaccines for viral diseases do in a human body is to boost the immune systems of the victims to outcompete the viruses in their bodies. While most of the African states and other nations around the globe await the invention of the viral vaccines for COVID-19, they may be able to curb the disease with the traditional measures that have been scientifically proven to reduce the severity of viral diseases which may be features of COVID-19. Spices that contain antioxidants may not cure COVID-19 but may count significantly in controlling the eruption of coronavirus pathogens and reduce its ability to outcompete its victim's 
immune system. Antioxidants stimulate one's antibodies reaction against strangely destructive antigens to somatic cells [23]. In our case the antigens are the SARS-COV which causes the SARS-COV-2.

\subsection{Ginger Roots}

Ginger is referred as among the most curative natural herbs ever existing in global/local regions. It helps to fight flu and/or treat common cold extremities, strengthen the body after extreme loss of blood, arthritis, sore throat, Joint pain and stiffness, muscle pains and soreness [24]. Among the people that initially succumbed to Covid-19, some had experienced illnesses that are controllable or completely cured by ginger content. It has a drastic ability to reduce the risks of one's exposure to uncontrollable COVID-19 as it reduces these physiological issues. The roots of ginger can be chewed raw or mixed with other herbal spices like Cinnamon, sesame oil, and mastic to counter the opportunistic diseases that affect the persons victimized by COVID-19. Consumption of ginger which contains Gingerol has been realized to boost immunity. It has been used in all forms of treatments in both modern china for diseases such as asthma, migraines, allergy and many other disorders [25].

\subsection{Lemon}

These are citric fruits available in most local regions and presumably known by most people globally. Medically, lemon is used to treat throat infections and fever [26]. They two are symptoms associated with SARS COV-2.

\subsection{Aloe Vera}

This natural herb has been scientifically proven to be among the natural herbs that are responsive in stimulating the immune system in human body [27]. This means that continuous consumption of Aloe juice will always keep the body active against infections and new attacks by diseases encompassing Severe Acute Respiratory Syndrome Coronaviruses. A component of Aloe Vera called Aloe Emodin was proved to prevent and reduce infectivity of viral attacks to human body and has an ability to engulf and inactivate all the viruses including influenza virus. The enveloped viruses were also found to be destroyed by another component of Aloe Vera referred to as Anthraquinone during Electron Micrograph examination done in laboratory [28]. Based on this examination, it is advisable that whether a patient is already tested or not, they should be taking Aloe Vera juice to rudiment or supplement their bodies with ample defense components to keep their bodies under anti-viral surveillance and viral pathogens destruction. All these natural herbs are locally and mostly freely available and harmless to human being if consumed. Therefore, since everyone is a potential victim of COVID-19, they should be taking Aloe Vera juice unconditionally to maintain viral protections/prevention and curative mechanisms in their bodies. Individuals with diabetes, kidney and heart diseases should not aloe Vera internally.

\section{Use of Upgraded Ventilation System}

While the COVID-19 patients are confined in the quarantines, they need proper and modern ventilation for fresh air. This will help to reduce transmission to other clients awaiting tests and the fortnight health confirmation in the secluded room like in Kenya where suspected persons are queued in the reserved rooms to be tested for further attention if infected. For instance, in Prince of Wales Hospital a midtwenty years gentleman who was undergoing treatment for Severe Acute Respiratory syndrome associated with the 2003 coronavirus disease transmitted the viral pathogens to 138 out of 156 individuals who entailed visitors, health attendants, and others who had a close contact with the person because the admission ward for seclusion was poorly ventilated [29].

\section{Susceptibility}

Though the vulnerable population was not vividly established in the first appearances of the SARS and MERSCoV which were homologically etiological diseases, the 2019 COVID situation occurs to be more harsh to some groups in terms of biological sex, age and health state of individuals contrary to the past epidemics [30]. This is because around 25 first people to die of SARS-COV-2 were found to be having other physiological disorders such as Diabetes, blood pressure controversies, heart malfunctions and kidney problems [21]. This reveals that any person, who happens to contract COVID19 while facing other immune-compromised conditions in their bodies, may not be able to recover from the illness due to readily weakened immunity. Therefore, it is recommendable that individuals consume natural or immune boosting diets that can help their antibodies to develop strong defense mechanisms to resist the infections.

Similarly, the cases that are related to SARS-COV which were experienced in 2002-2003 as Middle East Respiratory Syndrome Coronavirus (MERS CoV) affected typically the people who had physiological issues such as smokers, those with cardiovascular issues, and the ones who had chronic illnesses [31]. Since both viral diseases have a phylogenetic, structural and etiological homology, the patients who are in those circumstances are very likely to be infected with 2019 coronavirus disease.

In Singapore, stochastic modeling of SARS outbreak showed that the population which did not fully practice the control measures transmitted the virus to three new contacts from one primary individual. Approximately $80 \%$ of 201 SARS individuals had no sign of transmitting the virus but one person could infect more than 10 secondary individuals [32]. With this, it is important to observe that any person who has been experiencing poor health challenges, should strictly observe the set guidelines to shun COVID-19 infections.

(a) AGE

In Kenya, COVID-19 has been witnessed to severely infect people of all ages; children, youths and adults are infected. According to Wuhan City Health Committee [33], the first four deaths that occurred due to COVID-19 involved 
people above 60 years old. This record is generalizable to all cases across the world as it has been experienced where adults above 50 years are more susceptible to SARSCOV-2 infections. This may be due to different physiological, psychological and physical circumstances this category of people may be in.

\section{(b) IMMUNE SYSTEM}

The ability of a person's immune to protect or defeat pathogens depends with that person's strength of the immune system. For instance, during the SARS outbreak that occurred in Hong Kong 2002-2003, some patients served as the carriers of the viral disease [7]. They were observed to be spreading the pathogens while their symptoms and suffering took time to show up i.e. the incubation period was longer. Others were not easily infected even after being exposed to environments with the SARS victims [34]. In the current situation in Kenya, there is no $100 \%$ transmission, whereby, if a patient contacts health people, all the people do not get infected. This suggests that the immune system of the people is different in terms of strength. It may also be as a result of guidelines follow up by a subset of the people in contact with that victim.

According to [35], when it's cold weather and the temperatures are low, there is a rapid eruption of viral diseases due to depleted or weakened immune system. Lack of enough Melatonin and Vitamin-D acquired from the sunlight was found to be among the key aspects that count on this.

It is imperative to address the notion of Immunity on the grounds of viral co-infections, chronic infections and all sorts of illnesses that may attack individuals in relation to COVID19 exposure. In most cases the people who have been warring in other diseases like HVI/AIDS, cancerous diseases and all other defects that require strong immune related defenses, need to be observant and cautious. This is by strictly following the set rules and guidelines to curb, reduce and prevent contracting the SARS-COV (virus causing COVID-19). Suppose a patient who has been in any of these situations is examined and tested COVID-19 positive, he/she should be put in an attentive care unit/group which may need Strong immune boosting diets, vaccines or additional medical services to reinforce their white blood cells to defend their bodies successfully.

Another factor that has been noted for consideration is gender. This is grounded on the evidence that most of COVID-19 victims are the male patients. According to (36) the average of the infected population falls at 59 years old, lying between 15-89 years with male victims occupying 56$59 \%$ in the pie chart. This is evidential as it has been testified in Kenya where most of the victims are males.

\section{Inter-Hospital Transfer}

This study is led to this guideline by a case of about 50 years old Chinese male patient who faced unnoticed combined disorders and on being admitted first in Pingjin hospital, three illnesses were to be treated but the next day, the patient indicated symptoms of Coronavirus which appeared as Severe Acute Respiratory Syndrome which were realized to have been acquired from Pingjin due to close contact. With the requirement of urgent medical attention, the patient was transferred to Tianjin department for thorax disease and treated for two days, and finally to the department of infectious diseases where he died [37]. In Pingjin hospital the contact tracing techniques on the infected individuals revealed that 33 individuals had contracted COVID-19 from the 54 years old patient. This incident hints to the health practitioners and attendants that transfer of patients from quarantine or health center to another may facilitate rapid eruption of the COVID-19 to other patients, health staff and visiting health individuals who may happen to have a close contact with the victims of SARS-COV-2.

With the above scenario, it is logic to argue that there are several other issues that are linkable to inter-hospital transfer. These are those that extended the rate of SARS transmission such inaccurate and inappropriate diagnosis. For instance, the 54 years old Chinese male patient was transferred to Pingjin hospital before being examined to record his physiological status, a mistake which led to infection of 33 other patients and the network advanced. Therefore, it is recommendable that the health staff should purely isolate the coronavirus victims from the places where new suspects are secluded and separate the resources they must share will lead to contacts. The other very imperative notion to note is that instead of transferring patients, the equipment appropriate for treatment should be moved to the location of the illness rather than moving infectious patients to health environments where are likely to share the pathogens with uninfected people. Also, the victims need to be continuously investigated to ensure they are not co-infected with other pathogen to make sure that the intensity with which the pathogens of SARS-COV hit the immune system of the patients are reduced. Resources such as beddings too are supposed to be completely separated. Failure to this may lead to transforming these resources into the SARS pathogenic breeding zones for COVID-19.

The matters regarding inter-hospital transfer also concurs with the 1997 "20/80 empirical rule" that was established as a result of SARS-COV spreading. This theoretical principle argued that a small number of SARS-COV victims are likely to transmit the SARS pathogens to the highest number of people possible. This theory is backed up by the fact that a very few number of people got infected and circulated the Coronavirus disease to all other people who encountered them [38].

\section{Conclusion}

Most states have established stern principles to curb the spread of SARS-CoV-2. Amongst these Countries in Africa, Kenya has staged the available medical arsenal to lay their attack on the viral epidemic to secure the health lives of her citizens by educating them on guidelines, symptoms and effects of Coronavirus disease. With a slogan" Stay Home stay safe" which is meticulously contributing towards 
meaningful resistance against COVID-19. To completely halt the spreading of SARS-COV the additional steps described above may concretely count. This is because the viral disease doesn't have apparent victims or status of people who it targets. The most challenging tasks that are still required to be satisfied are the establishment of the degree of infectivity to other open areas such wounds and sexual organs. SARSCOVs are also found to thrive in their hosts and live there. The existing research so far have not established whether after death the corpse is left as a host or they die after certain duration of time. For it has been demonstrated that the viral pathogens are transmitted via droplets, the magnitude of the human wastes such as urine and stool should also be defined and emphasized as transmission pathways. Furthermore, the existing phylogenetic and genomic researches have responded to where the disease emerged, when the disease emerged, what caused it and partially what should be done to control COVID-19. While questions such as why the virus is more deadly to males than females needs to be answered.

\section{References}

[1] Cotten, M., Watson, S. J., Kellam, P., Al-Rabeeah, A. A., Makhdoom, H. Q., Assiri, A., Al-Tawfiq, J. A., Alhakeem, R. F., Madani, H., AlRabiah, F. A., et al. (2013). Transmission and evolution of the Middle East respiratory syndrome coronavirus in Saudi Arabia: a descriptive genomic study. Lancet 382, 1993-2002.

[2] Sasmita Poudel Adhikari, Sha Meng1, Yu-Ju Wu1, Yu-Ping Mao2, Rui-Xue Ye1, Qing-Zhi Wang1, Chang Sun1, Sean Sylvia3, Scott Rozelle4, Hein Raat5 and Huan Zhou1. (2020). Epidemiology, causes, clinical manifestation and diagnosis, prevention and control of coronavirus disease (COVID-19) during the early outbreak period: a scoping review Available online: http://doi.org/10.1185/s0249-020-005446-X.

[3] World Health Organization. Novel Coronavirus-Japan (exChina). Available online: https://www.who.int/ csr/don/16january-2020-novel-coronavirus-japan-ex-china/en/ (accessed on 19 January 2020).

[4] National Health Commission of People's Republic of China An update on the incidence of pneumonia with novel coronavirus infection as at 24:00 on 31 January 2020. http://www.nhc.gov.cn/xcs/yqfkdt/202002/84faf71e096446 fdblae44939ba5c528.shtml. Accessed 1 Feb 2020.

[5] Wuhan Municipal Health Commission. Wuhan Municipal Health and Health Commission's Briefing on the Current Pneumonia Epidemic Situation in Our City. Available online: http://wjw.wuhan.gov.cn/front/web/

Detail/2019123108989 (accessed on 19 January 2020).

[6] Zhao S, Lin Q. Ran J. Musa SS. Yang G. Wang W. et al. Preliminary estimation of the basic reproduction number of the novel coronavirus $(2019-\mathrm{nCoV})$ in China from 2019 to 2020: data-driven analysis in the early phase of the outbreak. Int J Infect Dis 2020b; 92: 214-7 Available from: http//:www.sciencedirect.com/science/article/pii/s1201971220 300539 .

[7] Kan, B.; Wang, M.; Jing, H.; Xu, H.; Jiang, X.; Yan, M.; Liang, W.; Zheng, H.; Wan, K.; Liu, Q.; et al. Molecular evolution analysis and geographic investigation of severe acute respiratory syndrome coronavirus-like virus in palm civets at an animal market and on farms. J. Virol. 2005, 79, 1189211900 .

[8] Ji, W.; Wang, W.; Zhao, X.; Zai, J.; Li, X. Homologous recombination within the spike glycoprotein of the newly identified coronavirus may boost cross-species transmission from snake to human. J. Med. Virol. 2020.

[9] Peiris JSM, Lai ST, Poon LLM, Guan Y, Yam LYC, Lim W, Nicholls J, Yee WKS, Yan WW, Cheung MT, Cheng VCC, Chan KH, Tsang DNC, Yung RWH, Ng TK, Yuen KY. 2003. Coronavirus as a possible cause of severe acute respiratory syndrome. Lancet 361: 1319-1325. http://dx.doi.org/10.1016/S0140-6736(03)13077-2.

[10] Menachery, V. D.; Yount, B. L., Jr.; Debbink, K.; Agnihothram, S.; Gralinski, L. E.; Plante, J. A.; Graham, R. L.; Scobey, T.; Ge, X. Y.; Donaldson, E. F.; et al. A SARS-like cluster of circulating bat coronaviruses shows potential for human emergence. Nat. Med. 2015, 21, 1508-1513.

[11] Lei-Ping Zeng, a Yu-Tao Gao, a Xing-Yi Ge, a Qian Zhang, a Cheng Peng, a Xing-Lou Yang, a Bing Tan, a Jing Chen, a Aleksei A. Chmura, b Peter Daszak, b Zheng-Li Shia. (2016). Bat Severe Acute Respiratory Syndrome-Like Coronavirus WIV1 Encodes an Extra Accessory Protein, ORFX, Involved in Modulation of the Host Immune Response.

[12] Woo PC, Lau SK, Lam CS, Lau CC, Tsang AK, Lau JH, Bai R, Teng JL, Tsang CC, Wang M, Zheng BJ, Chan KH, Yuen KY. 2012. Discovery of seven novel mammalian and avian coronaviruses in the genus Delta coronavirus supports bat coronaviruses as the gene source of Alpha coronavirus and Beta coronavirus and avian coronaviruses as the gene source of Gamma coronavirus and Delta coronavirus. J Virol 86: 3995-4008. http://dx.doi.org/10.1128/JVI.06540.

[13] WMHC. Wuhan Municipal Health and Health Commission's Briefing on the Current Pneumonia Epidemic Situation in Our City. $2020.2 \quad$ http://wjw.wuhan. gov.cn/front/web/showDetail/2019123108989. Accessed 1 Feb 2020 .

[14] John P. Cunha. fever in adults and children. 2019. https://www.medicinet.com/aches-pain-fever/article.htm.

[15] Justin, w. the wuhan coronavirus, climate change and future epidemics. 2020. https://time.com/5779156/wuhancoronavirus-climate-change.

[16] Wu JT, Leung K, Leung GM. Nowcasting and forecasting the potential domestic and international spread of the 2019-nCoV outbreak originating in Wuhan, China: a modelling study. Lancet 2020; Available from: http://www.sciencedirect.com/ science/article/pii/S1201971220300539.

[17] Maggie H. Wang et al. (2020). International Journal of infectious diseases: A conceptual model for the coronavirus disease 2019 (COVID-19) outbreak in Wuhan, China with individual reaction and governmental action.

[18] WHO. Infection prevention and control during health care when novel coronavirus (nCoV) infection is suspected. Interim Guidance Geneva2020. WHO/2019. $\mathrm{nCoV} / \mathrm{IPC} / \mathrm{v} 2020.1 \quad$ Available from: https://www.who.int/publications-detail/infection-preventionand-control-during-health-care-when-novelcoronavirus(ncov)-infection-is-suspected. 
[19] Bogoch II, Watts A, Thomas-Bachli A, Huber C, Kraemer MUG, Khan K. Pneumonia of unknown etiology in Wuhan, China: potential for international spread via commercial air travel. J Travel Med 2020; doi: http://dx.doi.org/10.1056/ NEJMoa2002032.

[20] Xintian Xu, Ping Chen, Jingfang Wang, Jiannan Feng, Hui Zhou, Xuan Li, Wu Zhong \& Pei Hao. Evolution of the novel coronavirus from the ongoing Wuhan outbreak and modeling of its spike protein for risk of human transmission. March 2020 Vol. 63 No. 3: 457-460 https://doi.org/10.1007/s11427020-1637-5.

[21] Xu, X., Chen, P., Wang, J., Feng, J., Zhou, H., Li, X., Zhong, W., and Hao, P. (2020). Evolution of the novel coronavirus from the ongoing Wuhan outbreak and modeling of its spike protein for risk of human transmission. SciChinaLifeSci63, 457-460. https://doi.org/10.1007/s11427-020-1637-5.

[22] Foster. S. Aloe Vera: the succulent with skin soothing Cell Protecting Properties," Herbs for Health Magazine, 1999. http://www.healthy.net/library/articles/hfh/Aloe.htm.

[23] Kim SO, Kundu JK, Shin YK, Park JH, Cho MH, Kim TY, Surh YJ. 2005. [6]-gingerol inhibits COX-2 expression by blocking the activation of p38 MAP kinase and NF-kappaB in phorbol ester-stimulated mouse skin. Oncogene. 15: 25582567.

[24] Wynn SG, Luna SPL, Liu H. 2001. Global acupuncture research: previously untranslated studies. Studies from Brazil. In: Schoen AM, editor. Veterinary acupuncture: ancient art to modern medicine. St Louis (MO): Mosby; p. 53-57.

[25] Shirin Adel PR, Prakash J. 2010. Chemical composition and antioxidant properties of ginger root (Zingiber officinale). JMPR. 4 (23): 2674-2679.

[26] Chaturvedi Dev, Shrivastava Rishi Raj suhane Nidhi. Basketful benefit of citrus lemon. INT Re. J. Pharm. 2016; 7 (6): 1-4 http://dx.doi.org/10.7897/2230-8407.07653.

[27] R. H. Davis, "Aloe vera: A Scientific Approach," Vantage Press Inc., New York, 1997.

[28] R. J. Sydiskis, D. G. Owen, J. L. Lohr, K. H. Rosler and R. N. Blomster, "Inactivation of Enveloped Viruses by Anthraquinones Extracted from Plants," Antimicrobial Agents and Chemotherapy, Vol. 35, No. 12, 1991, pp. 24632466.http://dx.doi.org/10.1128/AAC.35.12.2463.

[29] Tomlinson B, Cockram C. SARS: experience at Prince of Wales Hospital, Hong Kong. Lancet 2003; 361: 1486-7.

[30] Fehr, A. R.; Channappanavar, R.; Perlman, S. Middle East Respiratory Syndrome: Emergence of a Pathogenic Human Coronavirus. Annu. Rev. Med. 2017, 68, 387-399. [CrossRef] [PubMed].

[31] Rahman, A.; Sarkar, A. Risk Factors for Fatal Middle East Respiratory Syndrome Coronavirus Infections in Saudi Arabia: Analysis of the WHO Line List, 2013-2018. Am. J. Public Health 2019, 109, 1288-1293.

[32] Centers for Disease Control and Prevention (CDC) Severe accurate respiratory syndrome-Singapore, 2003. MMWR Morb Mortal Wkly Rep 2003; 52: 405-11.

[33] Wuhan City Health Committee (WCHC). Wuhan Municipal Commission on Health on pneumonia of new coronavirus infection $2020 \quad[21$ January 2020]. Available from: http://wjw.wuhan.gov.cn/front/web/showDetail/202001210908 3.

[34] Riley S, Fraser C, Donnelly CA, Ghani AC, Abu-Raddad LJ, Hedley AJ, et al. Transmission dynamics of the etiological agent of SARS in Hong Kong: impact of public health interventions. Science 2003; 300: 1961-6.

[35] Lipsitch M, Cohen T, Cooper B, Robins JM, Ma S, James L, et al. Transmission dynamics and control of severe acute respiratory syndrome. Science 2003; 300: 1966-70.

[36] Li Q, Guan X, Wu P, Wang X, Zhou L, Tong Y, et al. Early transmission dynamics in Wuhan, China, of novel coronavirus-infected pneumonia. N. Engl J Med. 2020.https://doi.org/10.1056/NEJMoa2001316.

[37] Wang ShX, Li YM, Sun BC, Zhang SW, Zhao WH, Wei MT, et al. The SARS outbreak in a general hospital in Tianjin, China - the case of super-spreader. Epidemiol Infect 2006; 134: 786-91.

[38] Woolhouse ME, Dye C, Etard JF, Smith T, Charlwood JD, Garnett GP, et al. Heterogeneities in the transmission of infectious agents: implications for the 30. design of control programs. Proc Natl Acad Sci U S A 1997; 94: 338-42. 